\title{
The effect of alkaline-surfactant on the wettability, relative permeability and oil recovery of carbonate reservoir rock: experimental investigation
}

\author{
Erfan Hosseini $^{1,3}$ (D) Farzad Hajivand ${ }^{1} \cdot$ Reza Tahmasebi $^{2}$
}

Received: 1 November 2018 / Accepted: 20 April 2019 / Published online: 25 April 2019

(c) The Author(s) 2019

\begin{abstract}
Due to the increasing demand and the price of hydrocarbon fuels, today, cost-effective enhanced recovery of oil and gas reservoirs has become one of the most interesting research topics. Since the Iranian reservoirs have a considerable potential to apply the chemical EOR processes, it seems that extensive research in this field is inevitable. One of the most important enhanced oil recovery techniques is injecting alkaline-surfactant into the reservoir. Although injecting alkaline-surfactant has been investigated in many researches, few studies reported on the effect of this process on the oil/water relative permeabilities which control the recovery performance. Today, the need for EOR processes is critical. One of the newest ideas for this respect is the concept of altering the rock wettability to more water wet. This phenomenon leads to making a path for oil in the larger routes, therefore increasing the recovery. In most cases, waterflooding has a low effect and by increasing the water production, the oil recovery becomes non-economical. In most studies, the effect of solution injection has been considered. In this study, we have investigated the effect of chemicals on interfacial tension and the wettability alteration based on relative permeability curves. In this work, using three surfactants, anionic (SDS), cationic (CTAB) and nonionic (Triton X-100), with sodium carbonate alkaline, relative permeabilities, wettability, IFT and the recovery efficiency in the porous media in the core scale have been investigated. The results show that cationic surfactant has the most effect on reduction in IFT and changing the wettability to water wetness, which has $70 \%$ recovery factor. Anionic surfactant has a greater effect on the reduction in interfacial tension in comparison with nonionic surfactant. Furthermore, nonionic surfactant has the most effect on changing the wettability to water wetness in comparison with anionic surfactant. Moreover, the recovery enhancement in the case of injection of alkaline-nonionic surfactant (67\%) is more considerable than alkaline-anionic (65\%).
\end{abstract}

Keywords Interfacial tension · Triton X-100 · Wettability $\cdot$ Surfactant $\cdot$ Alkaline

\section{List of symbols}

$f_{\mathrm{o}} \quad$ Oil fractional flow

$f_{\mathrm{w}} \quad$ Water fractional flow

$f_{\mathrm{w} 2} \quad$ Terminal water fractional flow

$k_{\mathrm{o}} \quad$ Effective permeability of oil (D)

$k_{\mathrm{w}} \quad$ Effective permeability of water (D)

$k_{\text {ro }} \quad$ Relative permeability of oil

$k_{\mathrm{rw}} \quad$ Relative permeability of water

Erfan Hosseini

e.hosseini19@put.ac.ir

1 Oil Industries Engineering and Construction Company (OIEC Group), Tehran, Iran

2 National Iranian Drilling Company (NIDC), Khuzestan, Iran

3 Petroleum Engineering Department, Abadan Faculty of Petroleum, Petroleum University of Technology (PUT), Abadan, Iran
$Q_{i} \quad$ Number of pore volume

$q_{i} \quad$ Injection rate $(\mathrm{cc} / \mathrm{min}, \mathrm{cc} / \mathrm{s})$

$q_{\mathrm{o}} \quad$ Oil flow rate

$q_{\mathrm{w}} \quad$ Water flow rate

$S_{\text {oi }} \quad$ Initial oil saturation

$S_{\text {or }} \quad$ Residual oil saturation

$\overline{S_{\mathrm{w}}} \quad$ Average water saturation

$S_{\mathrm{wD}} \quad$ Normalized water saturation

$S_{\mathrm{wf}} \quad$ Front water saturation

$S_{\mathrm{wi}} \quad$ Initial water saturation

$S_{\mathrm{w} 2} \quad$ Terminal water saturation

$\Phi$ Porosity

\section{Greek letters}

$\alpha \quad$ Angle between the system and horizontal plane

$\lambda_{\mathrm{o}} \quad$ Mobility of oil

$\lambda_{\mathrm{w}} \quad$ Mobility of water

$\frac{\lambda_{\mathrm{w}}}{\lambda^{-1}} \quad$ Average apparent viscosity 


$\begin{array}{ll}\overline{\lambda_{r}^{-1}} & \text { Apparent viscosity } \\ \mu_{\mathrm{o}} & \text { Oil viscosity }(\mathrm{cP}) \\ \mu_{\mathrm{w}} & \text { Water viscosity }(\mathrm{cP}) \\ \rho_{\mathrm{o}} & \text { Oil density }(\mathrm{g} / \mathrm{cc}) \\ \rho_{\mathrm{w}} & \text { Water density }(\mathrm{g} / \mathrm{cc}) \\ \sigma & \text { Interfacial tension }(\text { dyne } / \mathrm{cm})\end{array}$

\section{Introduction}

Due to the high cost of surfactant, using alkaline with surfactant in chemical injection to improve the efficiency of the process is taken into consideration (Mozaffari et al. 2017a; Hosseini et al. 2019). Alkaline reacts with the acid composition of the oil and produces surfactant that increases oil recovery by reducing interfacial tension between the injected fluid and oil, altering wettability of porous medium and forming emulsion spontaneously which releases the oil from the pores (Zolfagharloo et al. 2018; Darjani et al. 2017). Relative permeability curves have an important role in the performance of the reservoirs and also one of the most important input data for the simulation of oil reservoirs (Mozaffari et al. 2015; Hosseini 2019; Liu et al. 2017). The effect of alkaline-surfactant solution on relative permeability and the increment of recovery have been less studied by the authors (Mozaffari et al. 2017b). $\mathrm{Li}$ et al. (2004) studied surfactant adsorption on reservoir rock and its effect on surfactant injection process for enhanced oil recovery in. They used chemicals that reduce the surfactant adsorption and cause desorption of adsorbed material on reservoir rock. Their laboratory results showed that existence of $\mathrm{NaOH}$ and chemicals that cause surfactant desorption, decrease the interfacial tension between oil and water significantly. They injected these materials in four different cores to understand desorption process and its effect on oil production better. The results showed that oil recovery can increase 13\% more than before using surfactant-alkaline injection by adding chemicals which cause desorption of the materials ( $\mathrm{Li}$ et al. 2004). Han et al. (2006) by experimental results showed that core wettability influences the efficiency of oil displacement in water injection. They simulated the experimental results and compared them with the modeling results and showed that the optimum wettability in water injection is neutral state. They studied this important effect on chemical injection and observed in water wet state increment in recovery of original oil in place is $28.6 \%$, in neutral state it is $15.2 \%$, and in oil wet state it is $16.7 \%$. These results indicate that the reservoir rock wettability plays an important role in increment in complex chemical injection and water wet state has the highest percentage of recovery in three different wettability. They showed that wettability has no significant effect in the polymer injection and oil displacement (Han et al. 2006). Hunkey et al. (2010) implemented experiment on heavy oil by thirty different kinds of surfactants and alkaline. The results showed that by injecting alkaline-surfactant solution, the surface tension decreases and an emulsion between oil and water is processed and causes oil production without using thermal methods (Hunkey et al. 2010). Pei et al. (2012) studied injecting alkaline alone and injecting alkaline-surfactant simultaneously for heavy oil field. They found that tertiary oil recovery in injecting alkaline solution $4 / 0 \mathrm{wt} \%$ is equal to $21 \%$ of the original oil in place while adding surfactant to alkaline will increase oil recovery to $32 \%$. They also found that adding surfactants to alkaline solution reduces surface tension that has an important role in the mechanism of enhanced oil recovery (Pei et al. 2012). Experimental investigation of EOR using low salinity water and nanoparticles in one of southern oil fields in Iran was conducted by Hosseini et al. (2018). They concluded that silica hydrophilic nanoparticle suspension has the ability to reduce contact angle between oil phase and water phase (altering the solid surface to water wet) when nanofluid concentration increases. Souraki et al. (2019) investigated the wettability alteration of carbonate reservoir rock using amphoteric and cationic surfactants. The results of their experiments showed that the CTAB surfactant is more effective than HABSA surfactant to improve oil recovery from carbonate reservoirs. In another study, experimental investigation of ionic content effect on wettability alteration in smart water for enhanced oil recovery was done by Baradari et al. (2019). Their results demonstrate that increasing sulfate concentrations in smart brine causes a dominant alteration on wettability of dolomite rock. In a similar study, Hosseini (2019) investigated the effect of asphaltene deposition on oil relative permeability, rock wettability alteration and recovery in WAG process. He concluded that asphaltene deposition caused a noticeable increase in differential pressure across the core, so the differential pressure in "water break through" was increased 1.45 times in water injection and 1.92 times in WAG process. Use of nonionic surfactant almost prevented the increase in differential pressure in both methods. In this study, the effect of alkaline-surfactant on the wettability and relative permeability and its effect on increasing oil recovery are studied. In this case, the process of injecting alkaline-surfactant as a secondary recovery and tertiary recovery after water injection is investigated. Also, effect of three types of surfactants, anionic, cationic and nonionic, on oil recovery is studied.

\section{Material}

\section{Crude oil phase}

The oil used in this study is a dead oil sample which was obtained from one of Iranian south oil reservoirs. The oil has a viscosity of $3.31 \mathrm{cP}$ and a density of $0.82 \mathrm{~g} / \mathrm{cc}$. 


\section{Aqueous phase}

Distilled water and different solutions of water with 10,000 , 30,000 and $50,000 \mathrm{ppm} \mathrm{NaCl}$ salt concentration were prepared. Then, in each series of aqueous solutions, the most concentrated solution was diluted to prepare different concentrations of the surfactant in solution. By these solutions, $\mathrm{pH}$, density, IFT, wettability and core flood were measured.

\section{Surfactants}

The anionic surfactant used in this study is sodium dodecyl benzene sulfonate (SDS) $\left(\mathrm{CH}_{3} \mathrm{C}_{11} \mathrm{H}_{22} \mathrm{C}_{6} \mathrm{H}_{5} \mathrm{OSO}_{3} \mathrm{Na}\right.$ ) with molecular weight equal to $288.36 \mathrm{~g} / \mathrm{mol}$. The purity of this surfactant is more than $98 \%$. Cationic surfactant that has been used in this study is dodecyl trimethyl ammonium bromide $\left(\mathrm{C}_{12} \mathrm{TAB}\right)\left(\mathrm{C}_{12} \mathrm{~N}\left(\mathrm{CH}_{3}\right)_{3} \mathrm{Br}\right)$, with molecular weight equal to $364.45 \mathrm{~g} / \mathrm{mol}$ and purity more than $99 \%$. A nonionic surfactant, Triton X-100 $\left(\mathrm{C}_{14} \mathrm{H}_{22} \mathrm{O}\left(\mathrm{C}_{2} \mathrm{H}_{4} \mathrm{O}\right)_{10}\right)$ with molecular weight equal to $646.85 \mathrm{~g} / \mathrm{mol}$ and purity more than $99 \%$, is also used. These surfactants were purchased from DAE JUNG Chemicals Company. Chemical structure of the surfactants is shown in Fig. 1.

\section{Alkaline}

The alkaline used in this study is sodium carbonate $\left(\mathrm{Na}_{2} \mathrm{CO}_{3}\right)$. Sodium carbonate was purchased from Merck Company. Chemical structure of sodium carbonate is shown in Fig. 1.

\section{Core sample}

Core sample used for flooding tests was carbonate. Core sample is obtained from one of Iranian south oil reservoirs and cut to the little core samples in laboratory. Table 1 shows the dimensions of plugs used in this work.

\section{Rock properties measurements}

Before measuring porosity and permeability, plug samples must be cleaned of residual fluids and dried. Core samples were obtained from one of the Iranian carbonate reservoirs. A Soxhlet extraction method was used for cleaning of plug samples. A complete extraction took 8 days because of the low-permeability carbonate plug samples. After cleaning, the plug samples were put in an oven at a temperature of $140{ }^{\circ} \mathrm{C}$ for $24 \mathrm{~h}$. In this work, for porosity measurement, the helium porosimeter was used to determine the porosity of the plug samples. This method employs Boyle's law. Figure 2a depicts a schematic of helium porosimeter. Porosity properties of plug samples

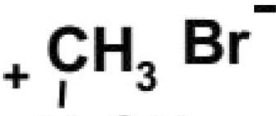 \\ $\mathrm{CH}_{3}\left(\mathrm{CH}_{2}\right)_{10} \mathrm{CH}_{2}-\mathrm{N}-\mathrm{CH}_{3}$ $\mathrm{CH}_{3}$}

(a)<smiles>CCCCCc1ccc(S(=O)(=O)O[Na])cc1</smiles>

(b)<smiles>CC(C)(C)CC(C)(C)c1ccc(OC(C)(C)CO[Tl])cc1</smiles>

(c)

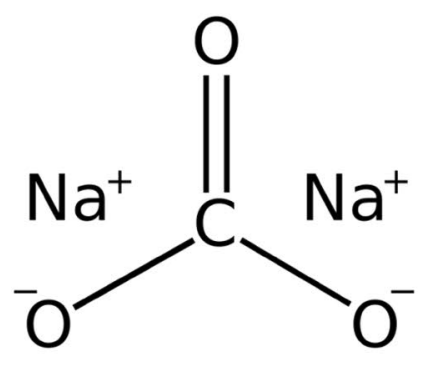

(d)

Fig. 1 Chemical structures of C12TAB (a), SDS (b), Triton X-100 (c), sodium carbonate $(\mathbf{d})$

Table 1 Plugs dimensions

\begin{tabular}{lll}
\hline Plug number & Length $(\mathrm{mm})$ & Diameter $(\mathrm{mm})$ \\
\hline 1 & 44.9 & 38.94 \\
2 & 41.62 & 38.94 \\
\hline
\end{tabular}


are provided in Table 2. Two jointed plugs were used as a core sample in permeability measurement experiment and waterflooding tests. After placing the core sample in the core holder, the overburden pressure was provided by water. Then, it was vacuumed by using a pump for $7 \mathrm{~h}$. After that, the core sample was saturated with gas oil, and finally, permeability was measured by passing gas oil as a fluid with known viscosity $(1.7 \mathrm{cP})$ through the core sample of measured dimensions. A schematic of permeability measurement apparatus is shown in Fig. 2b. Under different injection rates of gas oil, pressure drops across the core sample in the core holder were recorded. Then, a line through $\Delta \mathrm{p}$ versus $\mathrm{q}$ data was plotted, and finally, the absolute permeability of the core sample was calculated. Figure 3 shows the $\Delta p$ versus $q$ data and a line passes through these data. In this work, the unsteady-state technique was used to determine the relative permeability curves. Also, Jones and Roszelle graphical method was used to calculate relative permeability of oil and water based on production
Table 2 Porosities of plug samples

\begin{tabular}{ll}
\hline Plug number & $\Phi(\%)$ \\
\hline 1 & 11.01 \\
2 & 13.29 \\
\hline
\end{tabular}

data ("Appendix" section). Permeability of the core sample was calculated which was $0.4 \mathrm{md}$.

\section{Fluids properties measurements}

In this work, density of oil and brine for interfacial tension measurement was measured with DMA-45 of Anton Paar Company. For work in the range of $5-80{ }^{\circ} \mathrm{C}$ at ambient pressure, usually air and distilled water are used. Air and distilled water were used as standard substances for adjustment in these experiments. Results of the fluid density measurement are shown in Table 3. Then, for viscosity measurement,
Fig. 2 a Schematic diagram of helium porosimeter apparatus. b Schematic diagram of permeability measurement and flooding experiment (a)

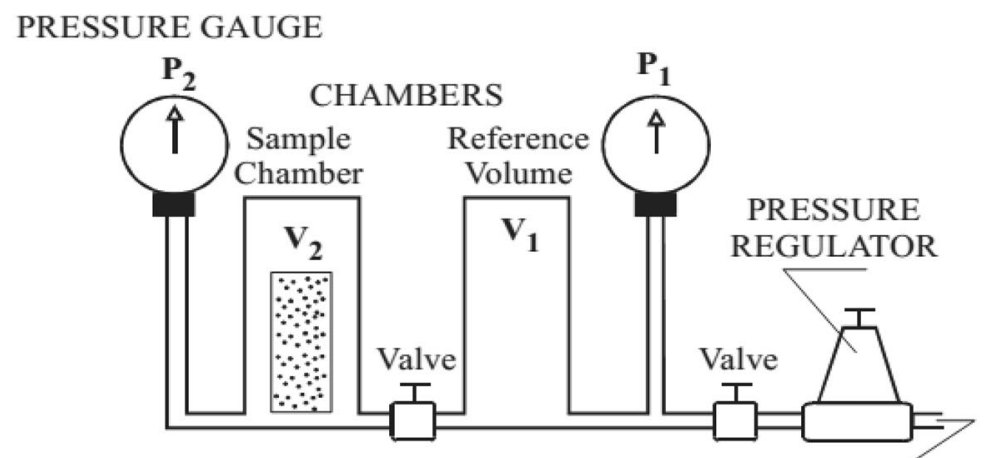

To gas pressure source

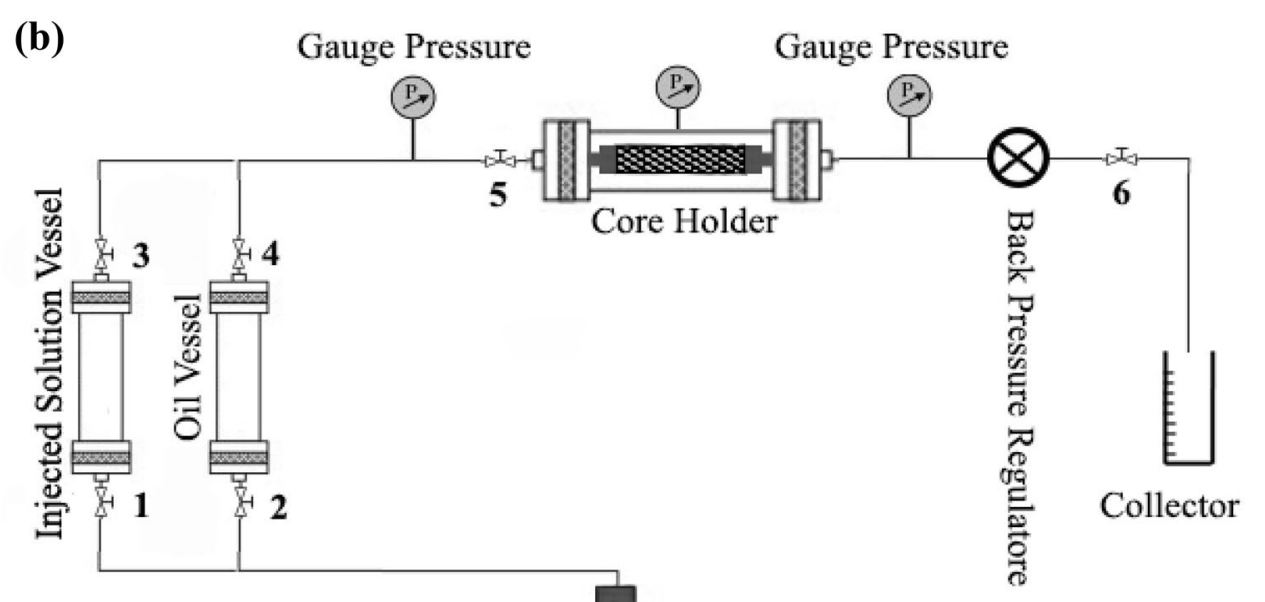


Fig. 3 Absolute permeability measurement (passing gas oil as a fluid with known viscosity $(1.7 \mathrm{cP}))$

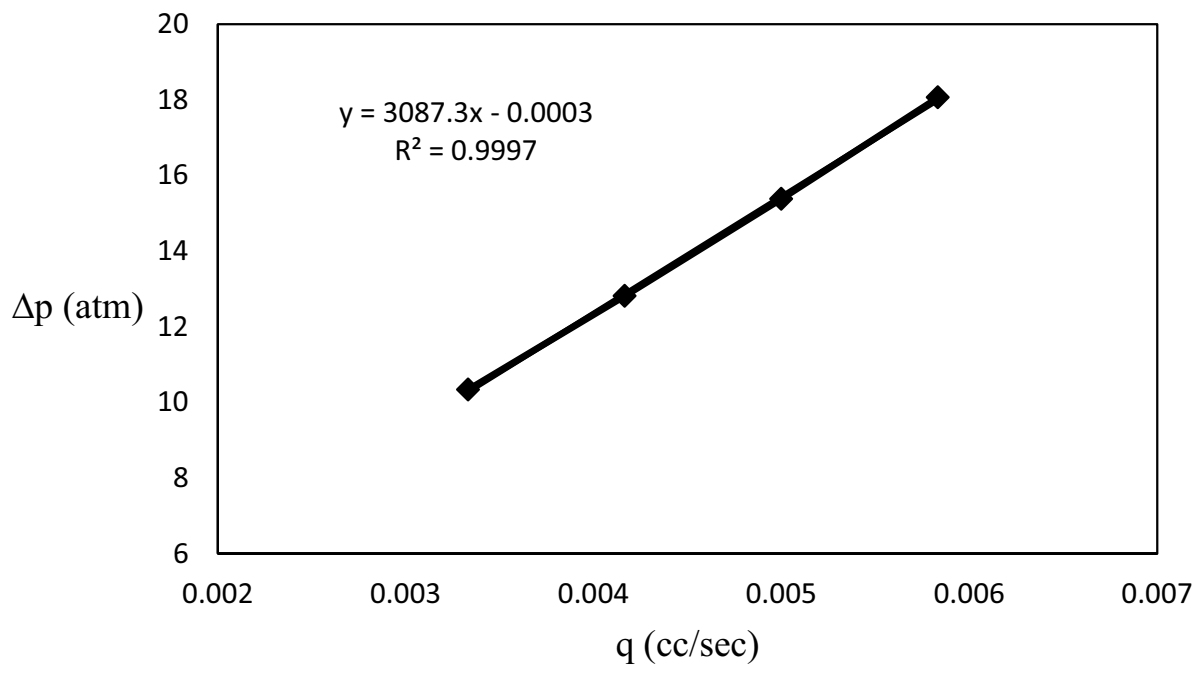

Table 3 Densities of the injected water and oil at $27^{\circ} \mathrm{C}$

\begin{tabular}{ll}
\hline Fluid & Density $(\mathrm{g} / \mathrm{cc})$ \\
\hline Injected water (distillated) & 1.01 \\
Alkaline $(0.8 \mathrm{wt} \%)$ and surfactant $(0.1 \mathrm{wt} \%)$ CTAB solution & 1.06 \\
Alkaline $(0.6 \mathrm{wt} \%)$ and surfactant $(0.1 \mathrm{wt} \%)$ SDS solution & 1.09 \\
Alkaline $(0.4 \mathrm{wt} \%)$ and surfactant $(0.1 \mathrm{wt} \%)$ TX-100 solution & 1.16 \\
Crude oil & 0.82 \\
\hline
\end{tabular}

Table 4 Viscosity measurement at $27^{\circ} \mathrm{C}$

\begin{tabular}{|c|c|}
\hline Fluid & $\begin{array}{l}\text { Dynamic } \\
\text { viscosity } \\
(\mathrm{cP})\end{array}$ \\
\hline Injected water (distillated) & 0.91 \\
\hline $\begin{array}{l}\text { Alkaline }(0.8 \mathrm{wt} \%) \text { and surfactant }(0.1 \mathrm{wt} \%) \text { CTAB solu- } \\
\text { tion }\end{array}$ & 1.171 \\
\hline Alkaline (0.6 wt $\%)$ and surfactant (0.1 wt $\%)$ SDS solution & 1.042 \\
\hline $\begin{array}{l}\text { Alkaline }(0.4 \mathrm{wt} \%) \text { and surfactant }(0.1 \mathrm{wt} \%) \mathrm{TX}-100 \\
\text { solution }\end{array}$ & 1.082 \\
\hline Crude oil & 3.31 \\
\hline
\end{tabular}

Cannon-Fenske viscometer is used. Table 4 summarizes results of the viscosity measurement of oil and water.

\section{IFT measurement}

In this study, in order to measure alkaline-surfactant solutions/oil interfacial tension values, spinning drop apparatus is used and for measuring surfactant solutions/oil and water/oil interfacial tension, pendant drop apparatus is used. All IFT tests were performed in ambient temperature and atmosphere pressure. In this project, oil/water interfacial tensions were determined at atmosphere pressure and ambient temperature. Two ISCO pumps were used in these experiments: one for injection of water into the chamber and another one for oil injection through capillary tube by constant flow rate. One pump was connected to the water cell and another to the oil cell. Water or surfactant solution was pumped into the IFT cell to full level. The spinning drop apparatus has been used in this study for measuring interfacial tension that is manufactured by Fars Enhanced Oil Recovery Technology Company. This apparatus is designed for measuring ultra-low interfacial tension with an acceptable accuracy. In this apparatus, a droplet of one fluid is injected into a capillary tube containing another fluid immiscible with it.

\section{Relative permeability measurement and flooding experiment}

\section{Equipment}

The equipment used in the work includes: ISCO pump, oil vessel, injected vessel, distillated vessel, back pressure regulator, core holder, valves, connections, collectors and gauge pressure. Flooding experiments were performed at room temperature of $30{ }^{\circ} \mathrm{C}$ and atmospheric pressure on cylindrical carbonate core sample, $38.94 \mathrm{~mm}$ in diameter and $86.52 \mathrm{~mm}$ in length. 


\section{Flooding tests}

The schematic of experimental apparatus is depicted in Fig. 3. After preparing and cleaning the core sample, it was placed in the rubber sleeve and put in the core holder. This sleeve was used as a connection in exert of overburden pressure, on the rock. In these experiments, the overburden pressure was provided by water (4200 psi). After placing the core sample in the core holder, it was vacuumed by using a pump for $7 \mathrm{~h}$ and then to measure the pore volume, water is injected into core holder under constant pressure of $500 \mathrm{psi}$. In this step, valves 1 and 3 should be opened while others were closed. When pressure reached $500 \mathrm{psi}$, valve 5 was opened. After that, the pump injects water until the injection rate becomes zero. According to volume of injected water, pore volume of the core sample was calculated. To reach $S_{\mathrm{wi}}$, injection of oil was initiated. In this step, valves 1 and 3 were closed while others were opened. The injection of oil was continued until no water was detected at the outlet. By recording the overall volume of output water and knowing the volume of initial water in the core sample, $S_{\mathrm{wi}}$ was determined. After these steps, the process of waterflooding initiated. According to Rapoport and Leas criterion of stabilization (Lut $\mu \mathrm{w} \geq 1)$ and by substitution length of the core sample and viscosity of injected water in this criterion, it was considered that the injection rate should be $0.15 \mathrm{cc} /$ $\mathrm{min}$. For water injection under constant injection rate, valves 2 and 4 were closed and other valves kept open. In each set of experiment with constant injection rate, pressure and the amount of produced water and oil in collectors were recorded with respect to the volume of injected water. In each waterflooding tests, the experiments are finished when there is no oil production at the outlet. After closing valves 1 and 3, solution of injected solution vessel was changed to the selective AS solution and experiment should be continued until that there is no oil production at the outlet. Secondary AS flooding was done as well as water flooding. After completion of the experiment for selective alkaline-surfactant, the core sample was cleaned with toluene (using Soxhlet method) and should be dried at the temperature of $140{ }^{\circ} \mathrm{C}$ for $24 \mathrm{~h}$ in an oven. After that, the core sample was used for alkaline solutions with different surfactants again.

\section{Results and discussion}

\section{Interfacial tension of alkaline surfactant systems}

One of the main mechanisms in alkaline-surfactant injection process is reducing interfacial tension. In order to achieve the lowest IFT, optimal concentration of alkaline-surfactant solution should be determined. So interfacial tension experiments have been performed with a spinning drop apparatus and the results are shown in Fig. 4, where IFT is plotted as a function of alkaline concentration to determine optimal concentration. In IFT experiments, the surfactant concentration is kept constant because of its high price and the concentration of the alkaline is changed during the process. In the solution that contains CTAB, the lowest IFT is achieved at the concentration of $0.8 \mathrm{wt} \%$ of $\mathrm{Na}_{2} \mathrm{CO}_{3}$. When SDS is used as a surfactant, concentration of $0.6 \mathrm{wt} \%$ of $\mathrm{Na}_{2} \mathrm{CO}_{3}$ gives the lowest IFT, and when the Triton $\mathrm{X}-100$ is used as a surfactant, concentration of $0.4 \mathrm{wt} \%$ of $\mathrm{Na}_{2} \mathrm{CO}_{3}$ gives the lowest IFT. Alkaline reacts with acidic components in crude oil and generates in situ surfactant that helps the main surfactant to reduce interfacial tension between water and oil (Green and Willhite 1998; Hosseini and Tahmasebi 2019). The bonds between water molecules and the hydrophilic head of surfactant and the bonds between oil and the lipophilic head of surfactant molecules are stronger than the bonds between oil
Fig. 4 Effect of alkaline concentration on the interfacial tension of different surfactants and oils

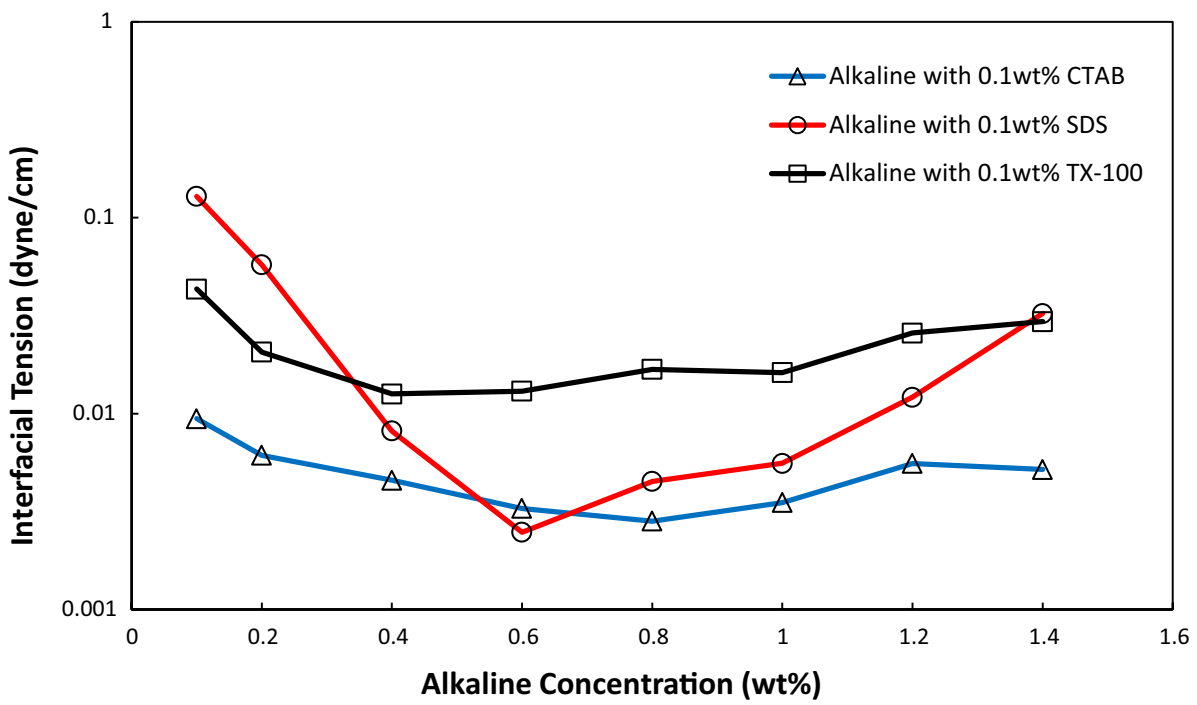


and water molecules, and this fact causes significant reduction in IFT.

\section{Relative permeability}

To obtain relative permeability values, the method of Jones and Roszelle is used. First, a plot of $\lambda_{\text {ave }}^{-1}$ versus PV is performed, and then, the equation between $\lambda_{\text {ave }}^{-1}$ and PV is obtained by curve fitting and by derivative of this equation, the slope of the tangent at any point is obtained. As a result, at any point a line can be obtained that the intercept is equal to $\lambda_{2}^{-1}$. Figure 5 a shows graph of $\lambda_{\text {ave }}^{-1}$ versus PV for water injection process, and Fig. 5b shows these graphs for AS injection. Relative permeability curves for water and alkaline-surfactant solutions are plotted in Figs. 6, 7 and 8. By comparing relative permeability curves of water and alkaline-surfactant solutions, a general upward movement in relative permeability curve is observed due to improvement in effective permeability of water and oil. Upward movement in oil relative permeability curves is due to changing rock wettability to a higher degree of water wetness. Oil relative permeability curve in alkaline solution and CTAB shows greater upward movement than other solutions. Surface of carbonate rock has positive charge, and alkaline reacts with the rock and changes the charge of the rock to the negative. Due to negative charge of surface of the rock and negative head of anionic surfactant, rock does not adsorb the anionic surfactant because of repulsion. But cationic surfactant like CTAB with positive head has adsorbed rock extremely, and it is the reason of wettability alteration of CTAB as cationic surfactant. Upward movement in water relative permeability curve is due to reduction in IFT between oil and water that allows water to move easier than oil. Increasing effective permeability of water will increase water injection rate and thus increase recovery rate. Figure 9 shows that water relative permeability values using SDS are higher than the others; it is obtained that when recovery rate is more important
Fig. 5 a Tangent construction for determining $\lambda_{2}^{-1}$ in water flooding before alkaline-surfactant CTAB flooding. b. Tangent construction for determining $\lambda_{2}^{-1}$ in alkaline-surfactant CTAB flooding
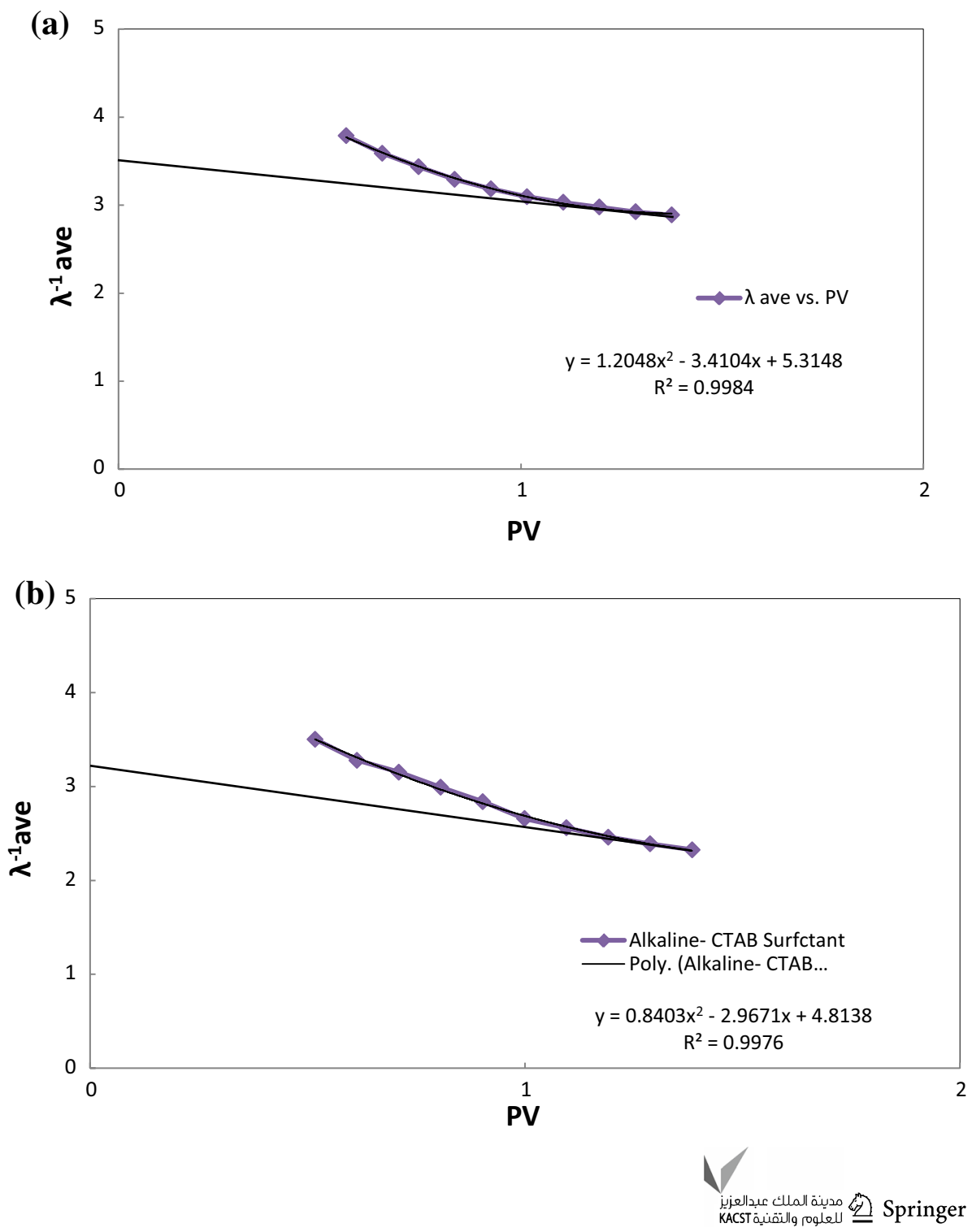
Fig. 6 Relative permeability curves for alkaline-surfactant TX-100

Fig. 7 Relative permeability curves for alkaline-surfactant CTAB

Fig. 8 Relative permeability curves for alkaline-surfactant SDS
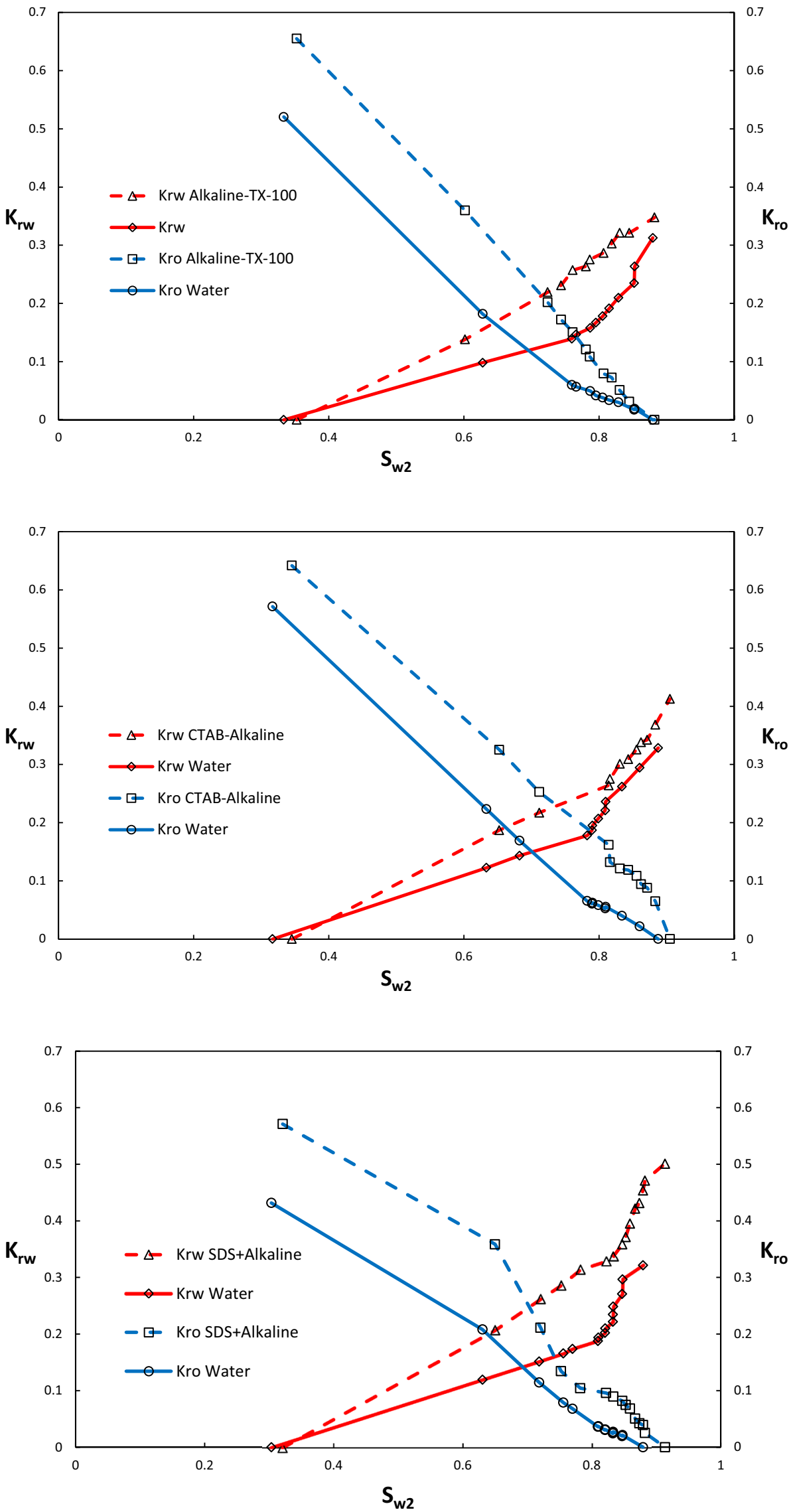
than total recovery, alkaline-surfactant SDS solution is best choice for injection.

\section{Wettability determination}

In this study, a qualitative method is used for determination of wettability. In other words, for qualitative evaluation of wettability, relative permeability curves are used for AS solutions with different surfactants. Forrest and Craig (1971) have presented a set of rules for classification of wettability based on relative permeability parameters obtained from the chart. These parameters are:

- Interstitial water saturation
- Saturation at which oil and water relative permeabilities are equal

- Relative permeability of water at the maximum water saturation

Craig's Rule of thumb that is used for determining strongly water-wet and strongly oil-wet reservoirs is summarized in Table 5. According to the rule of thumb specified by Craig, the results of the experiments conducted in this study for determining wettability of the samples are shown in Table 6. The results show that core samples were initially water wet and by alkaline-surfactant flooding, were more water wet. Solution that contains CTAB surfactant has greatest effect on wettability alteration through these solutions,
Fig. 9 Comparison of relative permeability curves for different surfactants

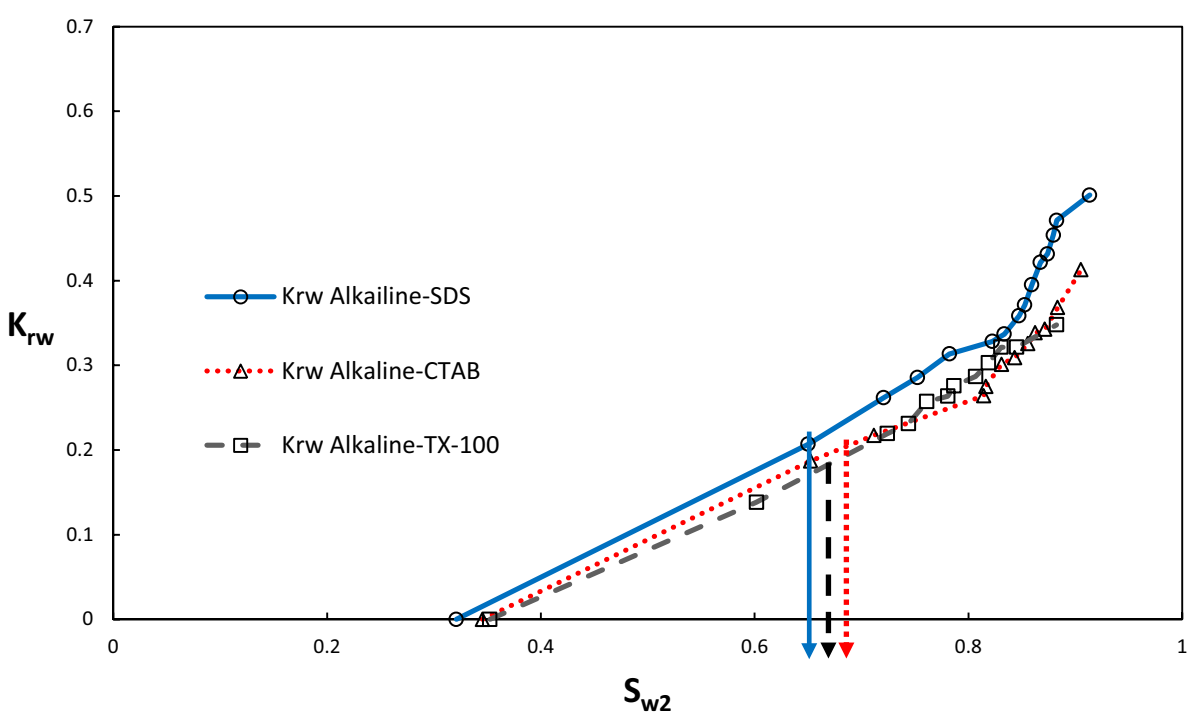

(a)

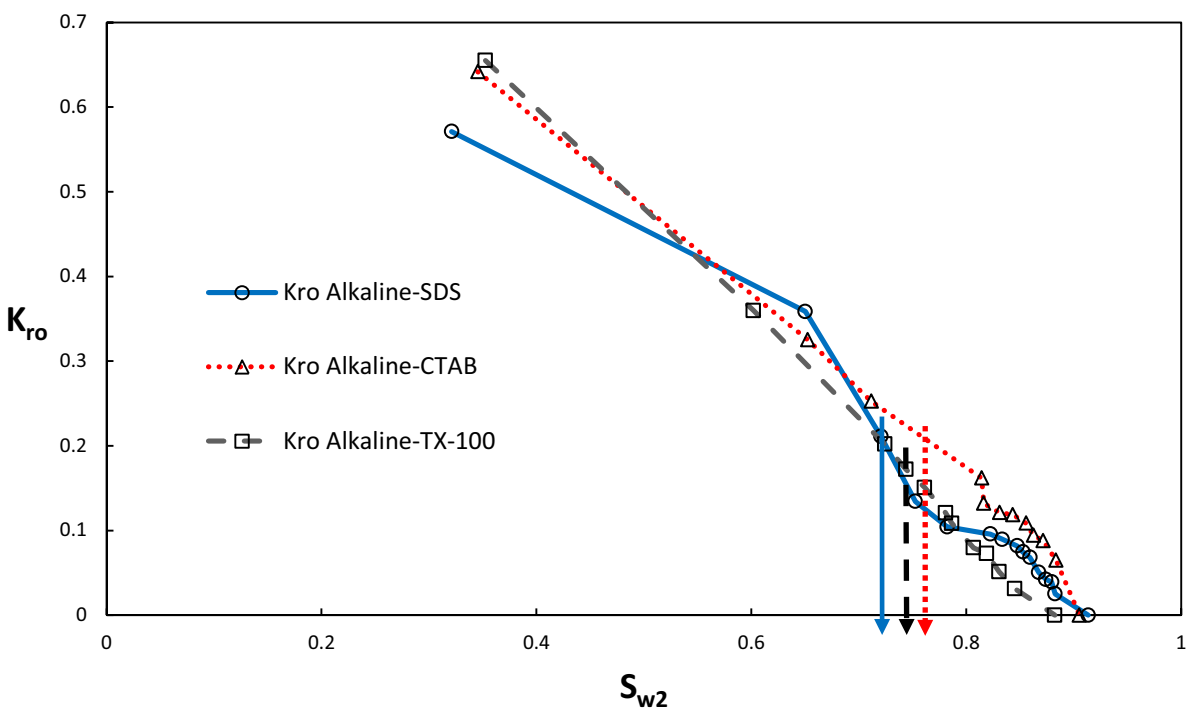

(b) 
Table 5 Craig's rule of thumb for determining wettability (Forrest and Craig 1971)

\begin{tabular}{lll}
\hline & Water wet & Oil wet \\
\hline$S_{\text {wi }}$ & Usually $>20-25 \%$ & Gener- \\
& & ally $<15 \%$. \\
& & Fre- \\
& & quently $<10 \%$ \\
$S_{\mathrm{w}}$ at $K_{\mathrm{ro}}=K_{\mathrm{rw}}$ & $>50 \%$ & $<50 \%$ \\
$K_{\mathrm{rw}}$ at $S_{\mathrm{or}}$ & Generally $<30 \%$ & $>50 \%$ and \\
& & approaching \\
& & $100 \%$ \\
\hline
\end{tabular}

Table 6 Results of tests to determine wettability

\begin{tabular}{llll}
\hline Sample & $S_{\mathrm{wi}}$ & $S_{\mathrm{w}}$ at $k_{\mathrm{ro}}=k_{\mathrm{rw}}$ & $k_{\mathrm{rw}}$ at $S_{\text {or }}$ \\
\hline Water & 0.3167 & 0.701 & 0.3284 \\
Alkaline-CTAB & 0.3454 & 0.738 & 0.4127 \\
Water & 0.3333 & 0.6958 & 0.3127 \\
Alkaline-TX100 & 0.3524 & 0.7152 & 0.3776 \\
Water & 0.3027 & 0.6925 & 0.3213 \\
Alkaline-SDS & 0.321 & 0.7029 & 0.501 \\
\hline
\end{tabular}

and SDS effect is not dominant, so solution containing CTAB is the best choice for wettability alteration.

\section{Performance of core flood experiments}

In order to investigate effect of chemical injection on oil recovery, several injections experiments have been performed. Initially, the water was injected to core as secondary oil recovery, and then, alkaline-surfactant with optimal concentrations was injected as tertiary oil recovery. Also alkaline-surfactant was injected as secondary oil recovery.

\section{Water and alkaline-surfactant injecting to core}

Figure 10 shows the oil recovery and pressure for water and alkaline-surfactant CTAB injection process. Oil recovery of water injection is about 59\%, and for AS injection, it has improved to $70 \%$. This improvement is due to IFT reduction between water and oil trapped after water injection. Wettability alteration to water wetness can also help increasing recovery because water occupies small pores and sweeps the oil to the larger pores. As it is demonstrated in Fig. 10, using AS causes $11 \%$ increase in recovery. Also by checking pressure profile, there is an increase in pressure with AS injection, which is due to formation of a massive bulk of oil. Figure 11 also shows the oil recovery and pressure for water and alkaline-surfactant TX-100 injection process. Oil recovery of water injection is about $59 \%$, and for AS injection, it has improved to $67 \%$. Increasing pressure with AS injection is due to formation of a massive bulk of oil. Figure 12 also shows the oil recovery and pressure, for water and alkaline-surfactant SDS injection process. According to the curve, oil recovery of water injection is about $59 \%$, and then, for AS injection, oil recovery has improved to $65 \%$. Figure 13 shows that in comparison with alkaline solutions with different surfactants used at tertiary EOR process, the maximum recovery was achieved by CTAB (70\%), and then by TX-100 (67\%) and SDS (65\%), respectively.

\section{Alkaline-surfactant injection as secondary recovery}

Comparison between IFT of solutions containing SDS and TX-100 shows that IFT value is lower for the solution containing SDS than TX-100. However, comparison between the wettability alteration to water wet and the viscosity of solutions containing SDS and TX-100 shows that the amount of wettability alteration is slightly more for solution containing TX-100. The results shown in Fig. 14 display
Fig. 10 Water and alkaline-surfactant $\mathrm{CTAB}$ injection

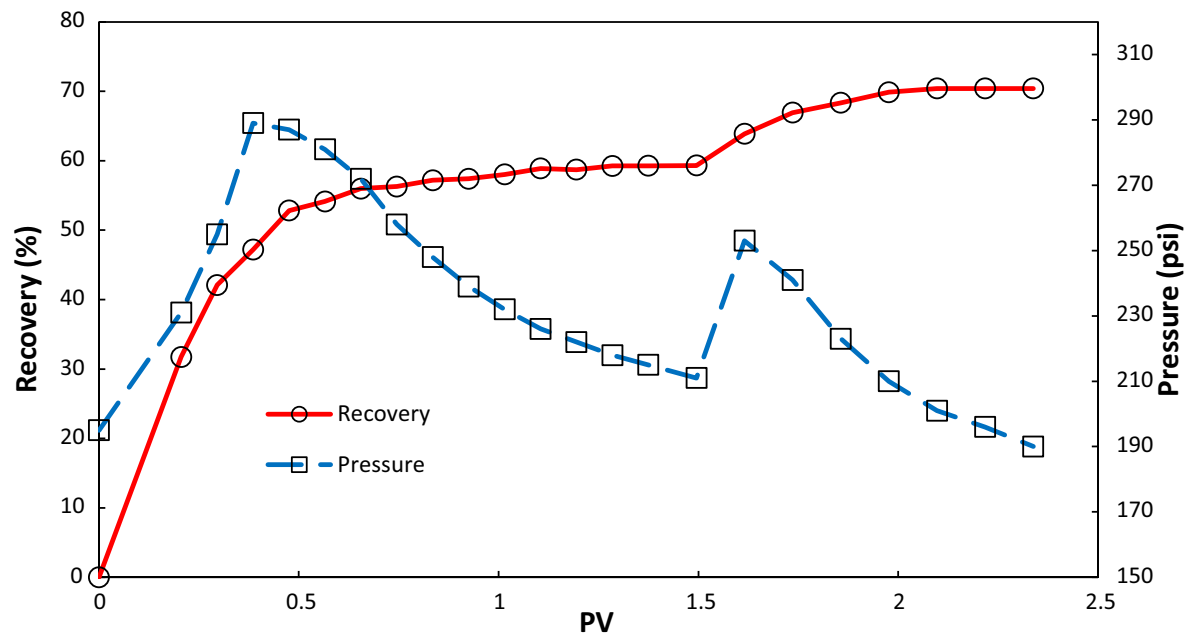


Fig. 11 Water and alkaline-surfactant TX-100 injection
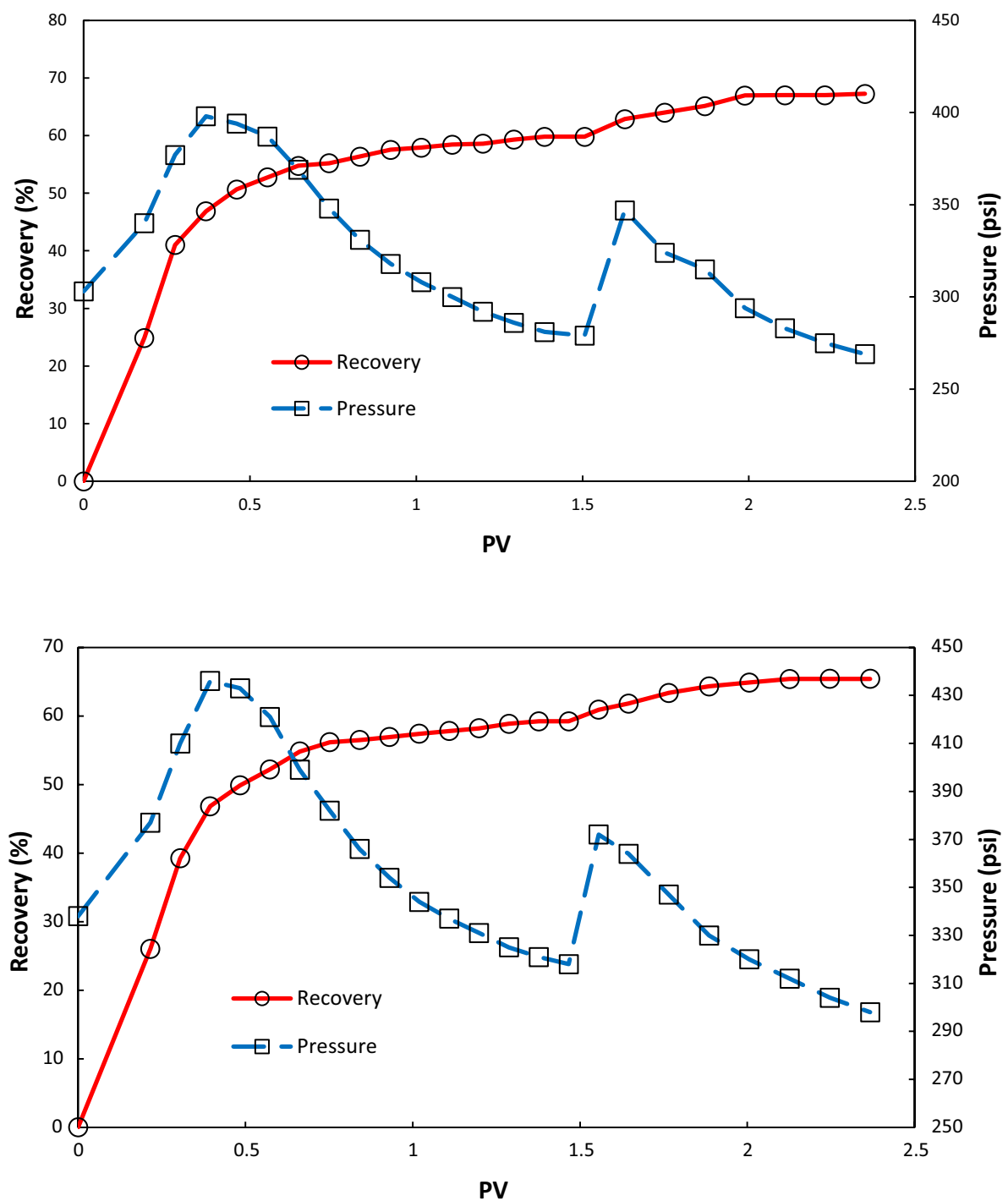

Fig. 12 Water and alkaline-surfactant SDS injection that recovery of alkaline-surfactant TX-100 is higher than recovery of alkaline-surfactant SDS. It can be concluded that the effect of the wettability altering to water wetness effect is greater than IFT effect on the recovery. Solution containing CTAB has a small value of IFT and has the greatest change in wettability to water wetness in comparison with other solutions, so it is expected that this solution has more recovery than others and this expectation is proved by experiments.

\section{Fractional flow}

The experimental relative permeability ratio of oil and water $\left(k_{\mathrm{ro}} / k_{\mathrm{rw}}\right)$ versus $S_{\mathrm{w} 2}$ for alkaline solution and three different surfactants is demonstrated in Figs. 15, 16 and 17. It can be observed from these figures that relative permeability ratio curves exhibit an exponential relationship with water saturation. By using the curve fitting, relationship between relative permeability ratio and saturation was achieved. These functions are used in fractional flow equation instead of relative permeability ratio in Eq. (1):

$$
f_{\mathrm{w}}=\frac{1}{1+\left(\frac{K_{\mathrm{ro}}}{K_{\mathrm{rw}}}\right)\left(\frac{\mu_{\mathrm{w}}}{\mu_{\mathrm{o}}}\right)}
$$

Shifting fractional flow curve from left to the right shows that wettability is altered to water wet. $k_{\mathrm{ro}} / k_{\mathrm{rw}}$ versus $S_{\mathrm{w} 2}$ at three different injection rates is plotted in Fig. 18. This figure shows that solution containing CTAB has more values of $k_{\mathrm{ro}} / k_{\mathrm{rw}}$ than other solutions for the same $S_{\mathrm{w} 2}$ because the core was more water wet in the presence of alkaline-surfactant CTAB and this fact improves our last discussion about wettability alteration. Experimental values of $f_{\mathrm{w}}$ and its values from Eq. (1) for alkaline and 
Fig. 13 Comparison of tertiary recovery for alkaline solutions and different surfactants
Fig. 14 Comparison of ultimate recovery for alkaline solutions and different surfactants
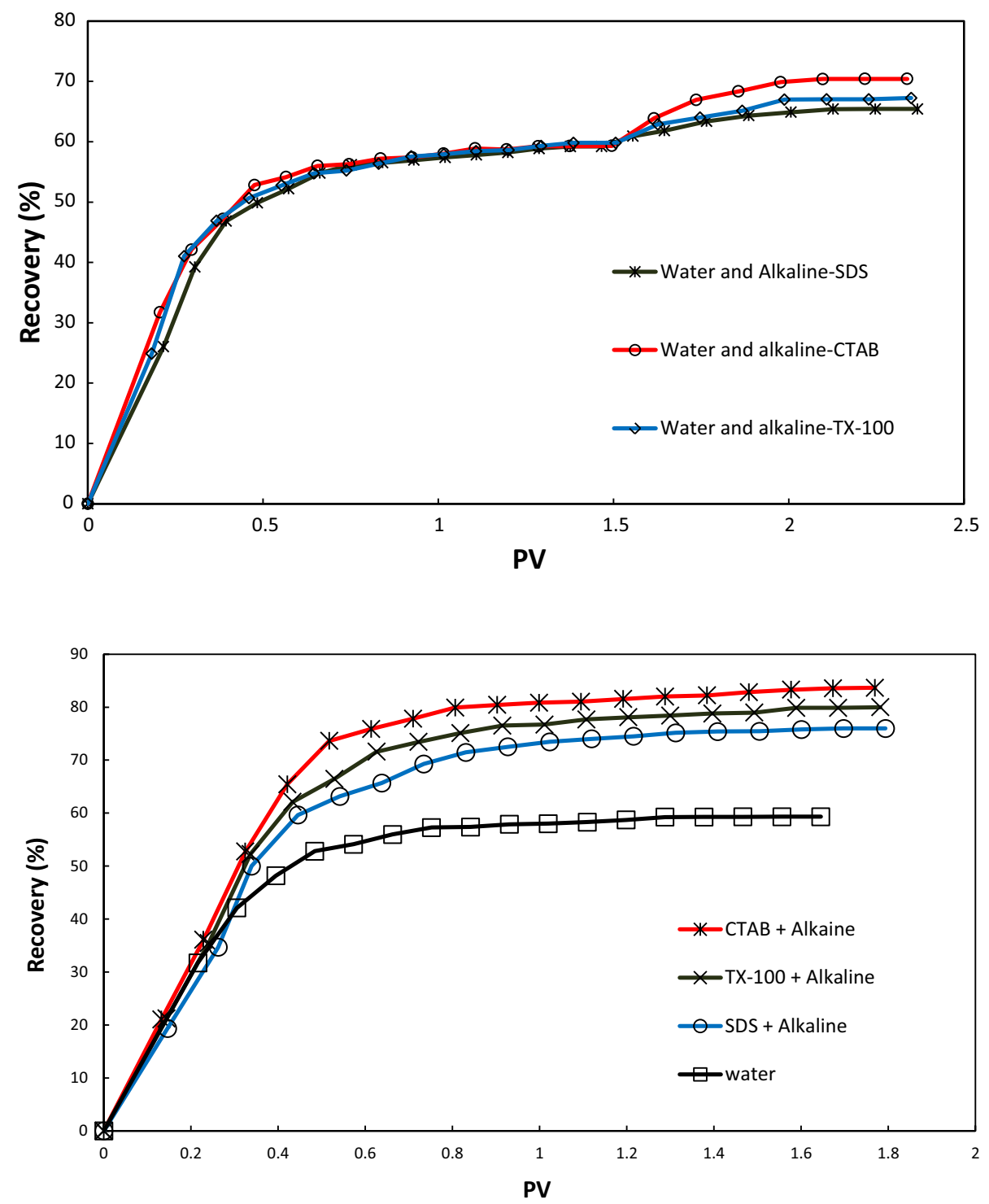

different surfactants are shown in Figs. 19, 20 and 21. Fitting empirical functions in Figs. 15, 16 and 17 can be used instead of $k_{\mathrm{ro}} / k_{\mathrm{rw}}$, in Eq. (1). In these figures, tangents have been drawn to $f_{\mathrm{w}}$ curve from $S_{\mathrm{wi}}$ intersecting the $f_{\mathrm{w}}$ curve at $\left(S_{\mathrm{wf}}, f_{\mathrm{wf}}\right)$. Intersect points for alkaline and three different surfactants are presented in Table 7. Difference between values of $S_{\mathrm{wf}}$ for alkaline and three different surfactants is due to different values of $S_{\text {wi }}$. The number of PVs needed to reach breakthrough $\left(Q_{\mathrm{ibt}}\right)$ is given by Eq. (2):

$Q_{\mathrm{ibt}}=\frac{\overline{S_{\mathrm{wf}}}-S_{\mathrm{wf}}}{1-f_{\mathrm{wf}}}$

$Q_{\text {ibt }}$ for alkaline and three different surfactants is shown in Table 7. Figure 19 shows that fractional flow curve of alkaline-surfactant CTAB is shifted to the right due to changing wettability to more water wet. Core with stronger water wetness has more $S_{\text {wi }}$ and less $S_{\text {or }}$ that change the initial and final point of the curve, which causes fractional flow curve to shift to the right. Figure 20 shows a little shift to the right due to same above-mentioned reason. As it is demonstrated in Fig. 21, there is no significant shift in fractional flow curve, which could be the result of little change in wettability. Reduction in IFT makes fractional flow curves more smoother. Then, by plotting fractional flow versus saturation, average saturation behind the front can be obtained. More average saturation shows less residual oil remained in the core and more oil is replaced by the solution. The value of the average saturation behind the front for SDS alkaline surfactant is equal to 0.806 , TX-100 alkaline surfactant is equal to 0.814 and for CTAB $\mathrm{AS}$ solution is equal to 0.845 . These values indicate that using CTAB AS leads to highest recovery and using SDS AS leads to lowest recovery. 


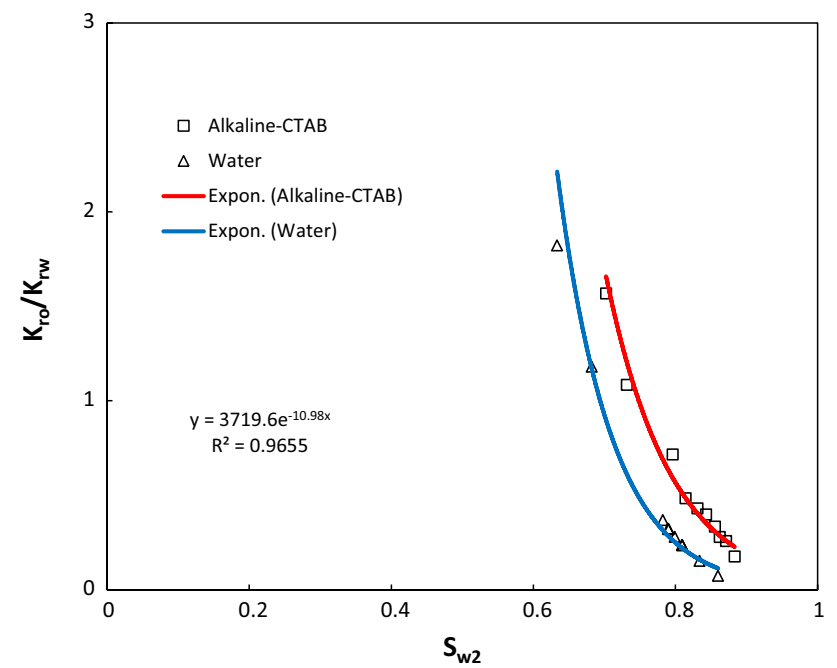

Fig. 15 Comparison of oil-to-water relative permeability ratio for water and alkaline-surfactant CTAB

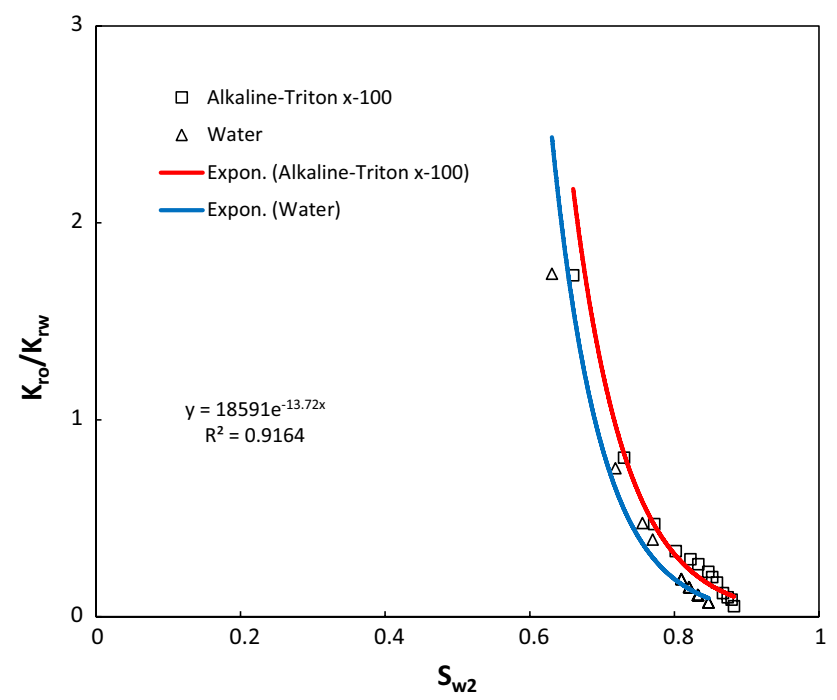

Fig. 16 Comparison of oil-to-water relative permeability ratio for water and alkaline-surfactant TX-100

\section{Conclusions}

Based on the experimental results discussed in this study, the following results are concluded:

- Increasing the alkaline concentration in the presence of surfactant causes a decrease in IFT toward a minimum.

- Comparing the performance of surfactants used in this study, the maximum reduction in IFT was performed by CTAB, and then by SDS and TX-100, respectively.

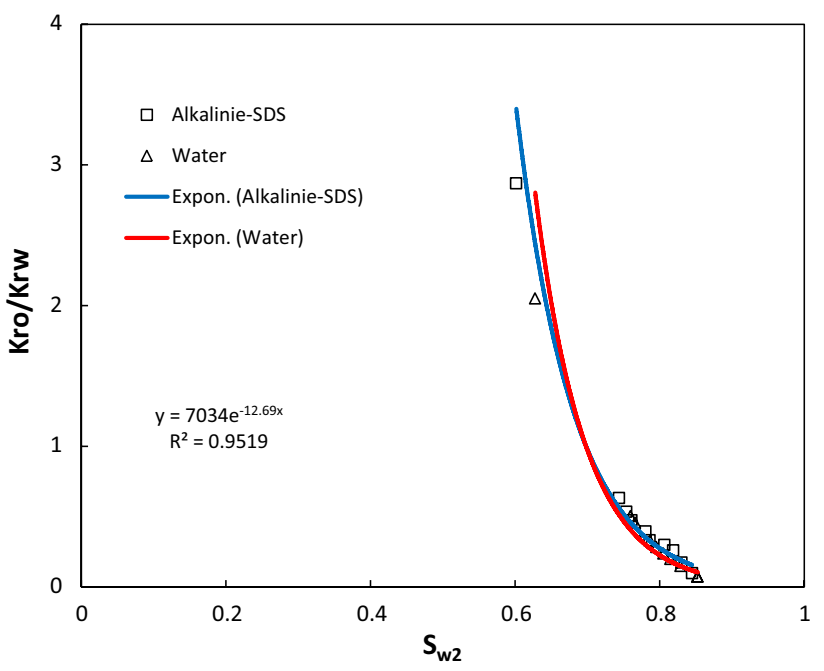

Fig. 17 Comparison of oil-to-water relative permeability ratio for water and alkaline-surfactant SDS

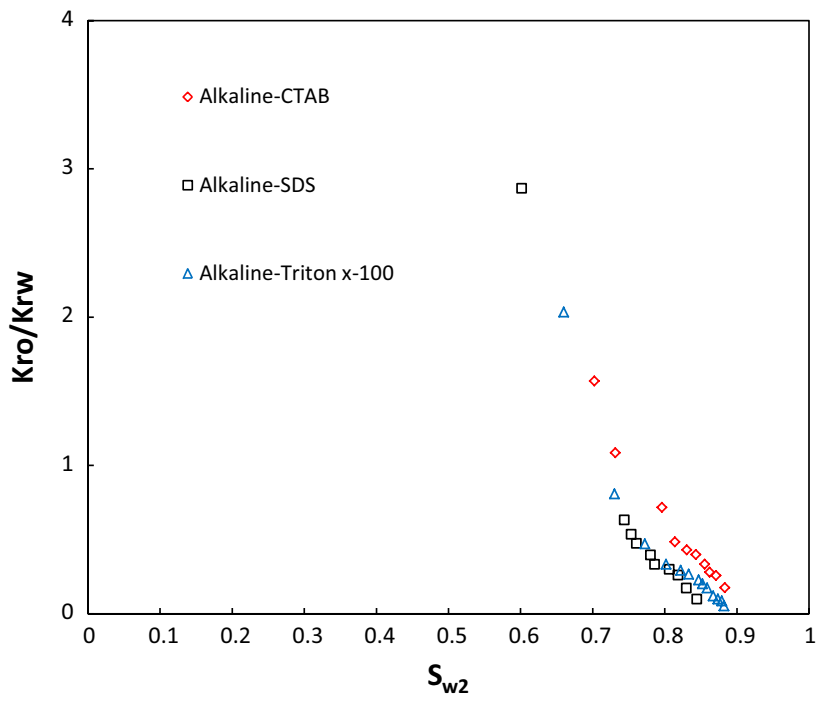

Fig. 18 Comparison of $K_{\mathrm{ro}} / K_{\mathrm{rw}}$ for the alkaline solution with different surfactants

- CTAB has a wide range of ultra-low IFT. As we know some amount of alkaline is adsorbed to the rock so we must inject an over concentrated solution which $\mathrm{CTAB}$ is suitable for this purpose.

- Comparing the performance of surfactants used in this study, the maximum wettability alteration toward water wet was performed by CTAB, and then by TX-100 and SDS, respectively.

- Wettability alteration has more effect on ultimate recovery in comparison with IFT reduction according to ultimate recovery curves. 


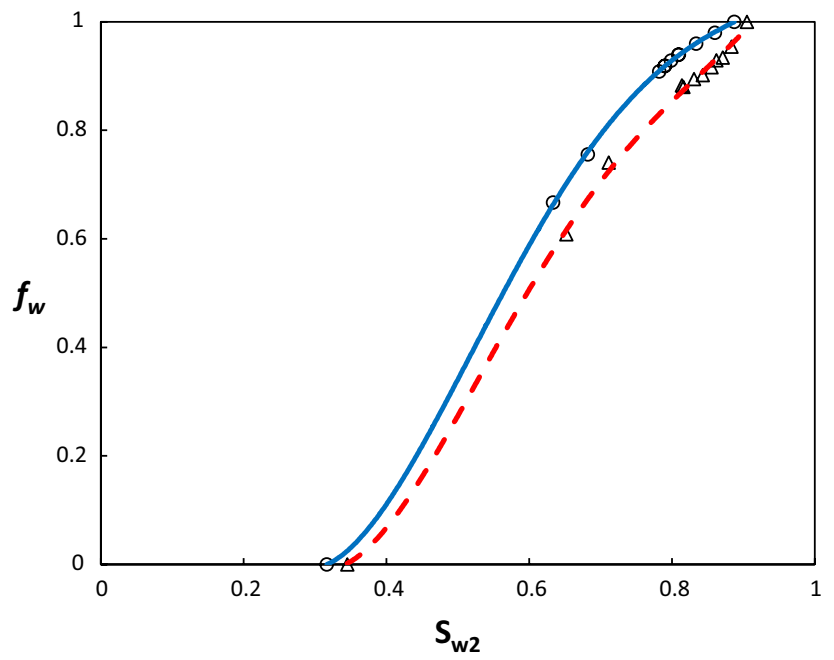

Fig. 19 Fractional flow curve for alkaline-surfactant $\mathrm{CTAB}$

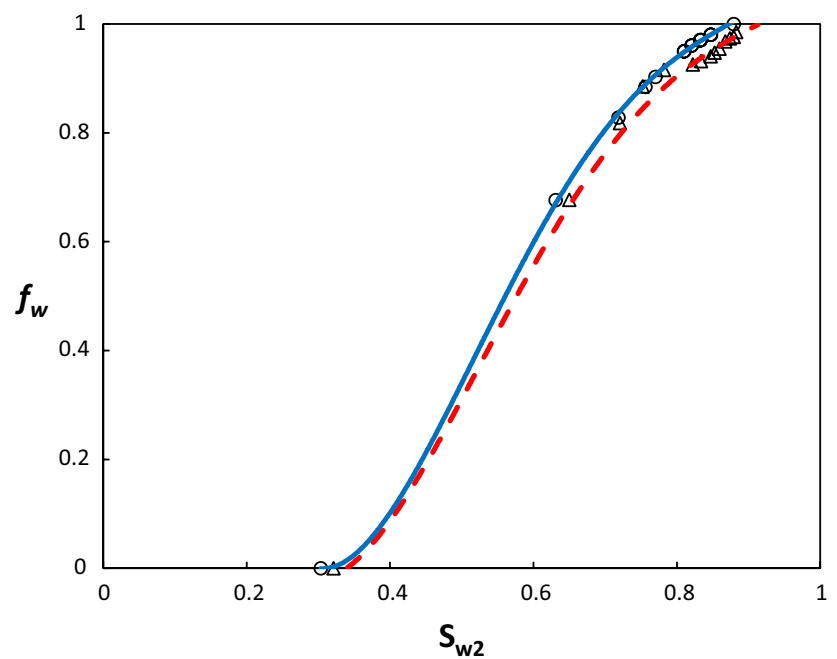

Fig. 20 Fractional flow curve for alkaline-surfactant TX-100

- Whenever the limiting parameter is production rate, SDS is a better choice because it has a more $k_{\mathrm{rw}}$ increment in comparison with other.

- Finally, comparing the performance of alkaline-surfactant flooding achieved in this project, the maximum ultimate recovery was obtained by CTAB, and then by TX-100 and SDS, respectively.

Acknowledgements We are grateful to the companies of Oil Industries Engineering and Construction (OIEC) and Sarvak Azar Engineering and Development (SAED) for financial support.

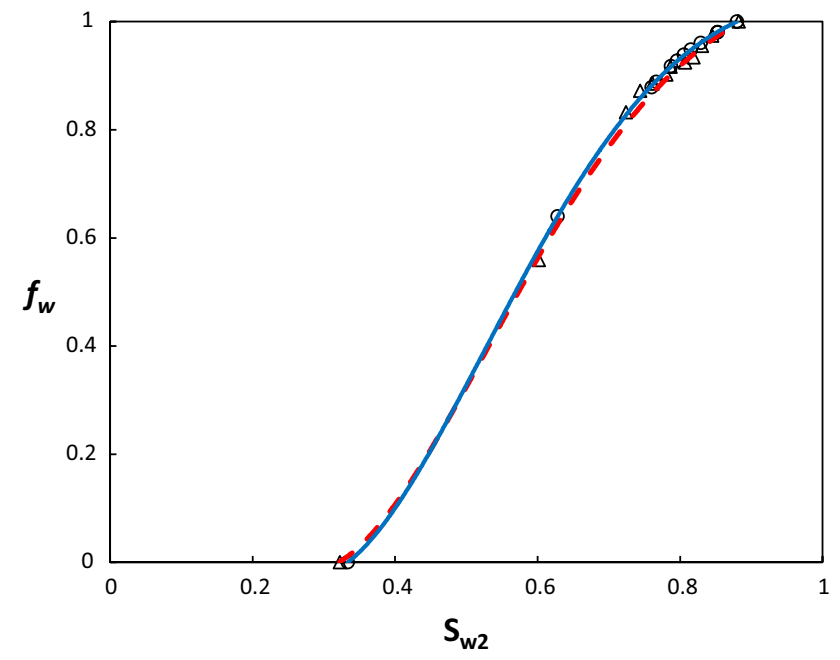

Fig. 21 Fractional flow curve for alkaline-surfactant SDS

Table 7 Intersects points $\left(S_{\mathrm{wf}}, f_{\mathrm{wf}}\right)$ for alkaline and three different surfactants

\begin{tabular}{lllll}
\hline Injection solutions & $\overline{S_{\mathrm{w}}}$ & $S_{\mathrm{wf}}$ & $f_{\mathrm{wf}}$ & $Q_{\mathrm{ibt}}$ \\
\hline Alkaline-surfactant CTAB & 0.845 & 0.665 & 0.605 & 0.45 \\
Alkaline-surfactant TX-100 & 0.814 & 0.63 & 0.673 & 0.56 \\
Alkaline-surfactant SDS & 0.806 & 0.615 & 0.696 & 0.62 \\
\hline
\end{tabular}

Open Access This article is distributed under the terms of the Creative Commons Attribution 4.0 International License (http://creativeco mmons.org/licenses/by/4.0/), which permits unrestricted use, distribution, and reproduction in any medium, provided you give appropriate credit to the original author(s) and the source, provide a link to the Creative Commons license, and indicate if changes were made.

\section{Appendix}

\section{Jones and Roszelle method}

Jones and Roszelle graphical technique, which is an industryaccepted procedure (Li et al. 2004), is illustrated as follows.

When a displacement is conducted at constant injection rate, at any instant of time the total pressure drop is related to fluid and rock properties by Eq. (3) (Li et al. 2004):

$\Delta p=\int_{0}^{L} \frac{\frac{q_{i}}{A} \mathrm{~d} x}{k_{\mathrm{b}}\left(\frac{K_{\mathrm{ro}}}{\mu_{\mathrm{o}}}+\frac{K_{\mathrm{rw}}}{\mu_{\mathrm{w}}}\right)}$

where $K_{\mathrm{b}}$ is the base permeability for the relative permeability data 
Define the effective or apparent viscosity and the average apparent viscosity with Eqs. (4) and (5):

$$
\begin{aligned}
& \lambda_{r}^{-1}=\left(\frac{K_{\mathrm{ro}}}{\mu_{o}}+\frac{K_{\mathrm{rw}}}{\mu_{\mathrm{w}}}\right)^{-1} \\
& \lambda_{r}^{-1}=\left(\frac{\int_{0}^{x} \lambda_{r}^{-1} \mathrm{~d} x}{\int_{0}^{x} \mathrm{~d} x}\right)
\end{aligned}
$$

By integrating Eq. (3) and using Eq. (5), at the outlet end of the core (point 2):

$\bar{\lambda}^{-1}=\frac{K_{b} A \Delta p}{q_{i} L}$

Computation of individual relative permeabilities requires values of the apparent viscosity at the $S_{\mathrm{w} 2}$. Thus, $k_{\mathrm{rw}}$ and $k_{\mathrm{ro}}$ can be calculated from Eqs. (7) and (8):

$K_{\mathrm{rw}}=\frac{\mu_{\mathrm{w}} f_{\mathrm{wz}}}{\lambda_{2}^{-1}}$

And,

$K_{\mathrm{ro}}=\frac{\mu_{\mathrm{o}} f_{\mathrm{oz}}}{\lambda_{2}^{-1}}$

where $\lambda_{2}^{-1}$ is the apparent viscosity at the outlet end of the core sample.

Only the average apparent viscosity is determined from experimental data. Jones and Roszelle developed a relationship between $\bar{\lambda}^{-1}$ and $\lambda_{2}^{-1}$ to compute values of $\lambda_{2}^{-1}$. They showed that drawn tangents to the graph of $\bar{\lambda}^{-1}$ versus $Q_{i}$ intersect the $Q_{i}=0$ at $\lambda_{2}^{-1}$. Thus, it is necessary to express $\bar{\lambda}^{-1}$ versus $Q_{\mathrm{i}}$.

\section{References}

Baradari A, Hosseini E, Soltani B, Jadidi N (2019) Experimental investigation of ionic content effect on wettability alteration in smart water for enhanced oil recovery. Pet Sci Technol 1:11. https://doi. org/10.1080/10916466.2018.1550509

Darjani Sh, Koplik J, Pauchard V (2017) Extracting the equation of state of lattice gases from random sequential adsorption simulations by means of the Gibbs adsorption isotherm. Phys Rev E 96:052803. https://doi.org/10.1103/PhysRevE.96.052803

Forrest F, Craig FF Jr (1971) The reservoir engineering aspects of waterflooding, 1st edn. H. L. Doherty Memorial Fund of AIME, Society of Petroleum Engineers, New York

Green WD, Willhite G (1998) Enhanced oil recovery. Henry L. Doherty Memorial Fund of AIME, Society of Petroleum Engineers, Dallas, pp 286-291

Han D, Yuan H, Wang H, Dong F (2006) The effect of wettability on oil recovery by alkaline/surfactant/polymer flooding. In: SPE annual technical conference and exhibition, 24-27 September, San Antonio, Texas. https://doi.org/10.2118/102564-MS

Hosseini E (2019) Experimental investigation of effect of asphaltene deposition on oil relative permeability, rock wettability alteration, and recovery in WAG process. Pet Sci Technol 1:11. https://doi. org/10.1080/10916466.2018.1482335

Hosseini E, Tahmasebi R (2019) Experimental investigation of performance of biosurfactant to wettability alteration and interfacial tension (IFT) reduction in microbial enhanced oil recovery (MEOR). Pet Sci Technol. https://doi.org/10.1080/10916466.2019.1575863

Hosseini E, Hajivand F, Yaghodous A (2018) Experimental investigation of EOR using low-salinity water and nanoparticles in one of southern oil fields in Iran. Energy Sour A Recov Util Environ Effects 40(16):1974-1982. https://doi.org/10.1080/15567 036.2018.1486923

Hosseini E, Hajivand F, Yaghodous A, Soltani R (2019) Experimental investigation of the effect of dispersed silica and alumina nanoparticles on oil-aqueous phase interfacial tension. Pet Sci Technol. https://doi.org/10.1080/10916466.2018.1476530

Hunkey R. M, Wu Y, Bai B, Dunn-Norman S (2010) An experimental study of alkaline surfactant flooding for ultra shallow heavy oil reservoirs. Society of Petroleum Engineers, SPE western regional meeting. https://doi.org/10.2118/132537-MS

Li J, Wang W, Gu Y (2004) Dynamic interfacial tension phenomenon and wettability alteration of crude oil-rock-alkaline-surfactant solution systems. In: SPE annual technical conference and exhibition, 26-29 September, Houston, Texas. https://doi. org/10.2118/90207-MS

Liu F, Darjani Sh, Akhmetkhanova N, Maldarelli Ch, Banerjee S, Pauchard V (2017) Mixture effect on the dilatation rheology of asphaltenes-laden interfaces. Langmuir 33(8):1927-1942. https:// doi.org/10.1021/acs.langmuir.6b03958

Mozaffari S, Tchoukov P, Atias J, Czarnecki J, Nazemifard N (2015) Effect of asphaltene aggregation on rheological properties of diluted athabasca bitumen. Energy Fuels 29(9):5595-5599. https ://doi.org/10.1021/acs.energyfuels.5b00918

Mozaffari S, Tchoukov P, Mozaffari A, Atias J, Czarnecki J, Nazemifard N (2017a) Capillary driven flow in nanochannels-application to heavy oil rheology studies. Colloids Surf A Physicochem Eng Asp 513:178-187. https://doi.org/10.1016/j.colsurfa.2016

Mozaffari S, Li W, Thompson C, Ivanov S, Seifert S, Lee B, Kovarik L, Karim MA (2017b) Colloidal nanoparticle size control: experimental and kinetic modeling investigation of the ligand-metal binding role in controlling the nucleation and growth kinetics. Nanoscale 9:13772-13785. https://doi.org/10.1039/C7NR04101B

Pei H, Zhang G, Ge J, Ding L, Tang M, Zheng Y (2012) A comparative study of alkaline flooding and alkaline/surfactant flooding for Zhuangxi heavy oil. In: SPE heavy oil conference Canada. Society of Petroleum Engineers. https://doi.org/10.2118/146852-MS

Souraki Y, Hosseini E, Yaghodous A (2019) Wettability alteration of carbonate reservoir rock using amphoteric and cationic surfactants: experimental investigation. Energy Sour A Recov Util Environ Effects 41(3):349-359. https://doi.org/10.1080/15567 036.2018 .1518353

Zolfagharloo A, Hosseini E, Ebrahimian E, Moradi S (2018) Experimental investigation of effect of palmitic acid as inhibitor on particle size of asphaltenes flocs using imaging techniques. Energy Sour A Recov Util Environ Effects 40(1):108-114. https://doi. org/10.1080/15567036.2017.1405118

Publisher's Note Springer Nature remains neutral with regard to jurisdictional claims in published maps and institutional affiliations. 